\title{
THE SELF-REFERENCING OXYGEN-SELECTIVE MICROELECTRODE: DETECTION OF TRANSMEMBRANE OXYGEN FLUX FROM SINGLE CELLS
}

\author{
S. C. LAND*, D. M. PORTERFIELD $\$$, R. H. SANGER AND P. J. S. SMITH \\ BioCurrents Research Center, Marine Biological Laboratory, Woods Hole, MA 02543, USA \\ *Present address: Department of Child Health, Ninewells Hospital and Medical School, Dundee DD1 9SY, Scotland, UK \\ †Author for correspondence (e-mail: mporterf@ mbl.edu)
}

Accepted 28 October; published on WWW 14 December 1998

\begin{abstract}
Summary
A self-referencing, polarographic, oxygen-selective microelectrode was developed for measuring oxygen fluxes from single cells. This technique is based on the translational movement of the microelectrode at a known frequency through an oxygen gradient, between known points. The differential current of the electrode was converted into a directional measurement of flux using the Fick equation. Operational characteristics of the technique were determined using artificial gradients. Calculated oxygen flux values matched theoretical values derived from static measurements. A test preparation, an isolated neuron, yielded an oxygen flux of $11.46 \pm 1.43 \mathrm{pmol} \mathrm{cm}^{-2} \mathrm{~s}^{-1}$ (mean \pm S.E.M.), a value in agreement with those available in the literature for single cells. Microinjection of metabolic substrates or a metabolic uncoupler increased oxygen flux, whereas microinjection of KCN decreased oxygen flux. In the filamentous alga Spirogyra greveilina, the probe could

easily differentiate a $16.6 \%$ difference in oxygen flux with respect to the position of the spiral chloroplast $\left(13.3 \pm 0.4 \mathrm{pmol} \mathrm{cm}^{-2} \mathrm{~s}^{-1}\right.$ at the chloroplast and $11.4 \pm 0.4 \mathrm{pmol} \mathrm{cm}^{-2} \mathrm{~s}^{-1}$ between chloroplasts), despite the fact that these positions averaged only $10.6 \pm 1.8 \mu \mathrm{m}$ apart (means \pm S.E.M.). A light response experiment showed realtime changes in measured oxygen flux correlated with changes in lighting. Taken together, these results show that the self-referencing oxygen microelectrode technique can be used to detect local oxygen fluxes with a high level of sensitivity and spatial resolution in real time. The oxygen fluxes detected reliably correlated with the metabolic state of the cell.

Key words: oxygen-selective microelectrode, oxygen flux, single cell, metabolism, mitochondria, mitochondrial disease, neuron, photosynthesis.
\end{abstract}

\section{Introduction}

Organisms and tissues are invariably composed of heterogeneous cell types, and understanding the role of these constituents is key to discerning normal physiological function from abnormal developments in disease states. For cellular metabolism, this is a particularly appropriate challenge. Mitochondrial dysfunction is increasingly perceived either as an underlying cause of a disease, as in human female agedependent infertility (Keefe, 1997), or as a consequence of early damage, as in apoptosis (Mignotte and Vayssiere, 1998), and is implicated in several neural degenerative diseases (Sims, 1996). Indeed, there is now a burgeoning field studying diseases of the mitochondria (Suomalainen, 1997). Despite this, there remains a gap in the techniques available for studying oxygen metabolism at the single-cell level, let alone with a spatial resolution capable of identifying focal points of oxygen flux within a single cell. One interesting and original approach by Poitry et al. (1996) succeeded in measuring the rate of oxygen consumption of one of the most metabolically active vertebrate cells, the retinal cell. This was accomplished by confining the cell in a glass pipette and monitoring the drop in oxygen partial pressure at the orifice using a microelectrode.
In the work presented here, we set out to devise an advanced microelectrode technique that would allow real-time measurement of single-cell transmembrane oxygen flux with square micrometer spatial resolution around the entire nonadhering surface of the cell.

Oxygen measurements provide a general indicator of many aspects of cellular metabolism and physiology. Davies and Brink (1942) first described the use of oxygen microelectrodes for direct measurement of tissue oxygenation. Later, the size of these electrodes was miniaturized with the goal of measuring intracellular $\mathrm{O}_{2}$ concentrations (Whalen et al., 1967), and they have since seen widespread use and some further development (Gnaiger, 1983; Armstrong, 1994). However, an invasive oxygen electrode technique can introduce experimental errors (Silver, 1967; Whalen, 1974; Schneiderman and Goldstick, 1978), the most significant of which is the induction of a damage response in the tissue or cell being probed. These obstacles to the study of mitochondrial function and cellular oxygen consumption would in many ways be solved if the oxygen level immediately outside the plasma membrane or, in the case of a plant, the cell 
wall could be sampled. A non-invasive self-referencing electrode technique was first described by Jaffe and Nuccitelli (1974) for measuring extracellular electrical fields around a single cell. This approach was later adapted for use with a $\mathrm{Ca}^{2+}$-selective electrode (Kühtreiber and Jaffe, 1990). We now report the operation of a self-referencing oxygen microelectrode for measuring extracellular oxygen flux in real time.

Simple diffusion sets the upper limits for the transfer of extracellular oxygen to the mitochondrial matrix (Krogh, 1919). In its simplest form, the movement of oxygen into a cell and through the cytoplasm is described by the Fick equation:

$$
J=-D \frac{\Delta C}{\Delta r},
$$

where $J$ is the flux rate $\left(\mathrm{molcm} \mathrm{cm}^{-2} \mathrm{~s}^{-1}\right), D$ is the diffusion coefficient $\left(\mathrm{cm}^{2} \mathrm{~s}^{-1}\right), \Delta C$ is the concentration difference (mol) and $\Delta r$ is the distance of measurement $(\mathrm{cm})$. The diffusion coefficient is a physical constant that varies according to the temperature and the solubility of oxygen. Although the value of $D$ inside the cell is a matter of continuing debate (Dutta and Popel, 1995), the value of $D$ outside the cell is equal to the diffusion coefficient of oxygen through water $\left(2.51 \times 10^{-5} \mathrm{~cm}^{2} \mathrm{~s}^{-1}\right.$ at $25^{\circ} \mathrm{C}$ and $101.3 \mathrm{kPa}$; Boag, 1969). Given that $D$ represents a predictable constant outside the cell, if $\Delta C / \Delta r$ can be determined, a reliable measure of oxygen flux near the cell may be obtained.

The self-referencing oxygen microelectrode enables the continuous measurement of $\Delta C / \Delta r$ from distinct regions next to the plasma membrane around a single cell. This allows sensitive and non-invasive measurement of oxygen flux for single cells by the translational movement of a Whalen-type oxygen-selective polarographic microelectrode through the oxygen gradient within the unstirred layer next to the cell membrane. The electrode tip (diameter of $2-3 \mu \mathrm{m}$ ) moves through the extracellular oxygen gradient at a known frequency and between points a known distance apart. By signalaveraging the current obtained at each position, then referencing the signals together, a differential current is obtained (in fA) that can be converted into a directional measurement of flux using the Fick equation. Referencing the signals in this manner confers the advantage that sources of interference caused by random drift and noise are effectively filtered from the signal and fluxes can be monitored in real time.

Here, we report the design, operating characteristics, spatial resolution and biological application of a self-referencing polarographic (Serp) oxygen microelectrode. We show a correlation between the derived oxygen flux around artificial sources and sinks with those measured directly by the new system. We further report characteristics of oxygen fluxes measured from isolated neurons of Aplysia californica and filaments of Spirogyra greveilina. A preliminary report on this technology, as applied to retinal cells, was presented at the Marine Biological Laboratory summer meeting in 1997 (Malchow et al., 1997).

\section{Materials and methods \\ The self-referencing oxygen electrode system}

The rig design and mode of electrode movement are similar to those originally described for self-referencing ion-selective (Seris) electrodes (Kühtreiber and Jaffe, 1991; Smith et al., 1994; Smith, 1995) and are described schematically in Fig. 1. The rig was constructed around an Axiovert 10 (Zeiss) inverted microscope fitted with a stage plate upon which the head-stage and translational motion control system were mounted. The latter consisted of Newport 310 series translation stages arranged in an orthogonal array and driven by size 23 linear stepper motors. This arrangement provided nano-to-millimeter resolution of movement of the head-stage in either a squarewave oscillation or single-step mode. Control over movement was achieved by the computer using IonView software. The entire assembly was mounted on an anti-vibration table and housed within a Faraday box. This box was thermally insulated and equipped with a temperature control system. The motion controllers, temperature controllers, head-stage and main amplifiers, as well as controlling software, are products of the BioCurrents Research Center (MBL, Woods Hole, MA: www.mbl.edu/BioCurrents).

Membrane-tipped, Whalen-style, polarographic oxygen microelectrodes with a tip diameter of $2-3 \mu \mathrm{m}$ were purchased from Diamond General Development Corp. (model 723, Ann Arbor, MI). A Ag/AgCl return electrode completed the circuit in solution via a $3 \mathrm{~mol}^{-1} \mathrm{KCl} / 3 \%$ agar bridge. When polarized continuously with a voltage sweep from -1.0 to $0 \mathrm{~V}$, optimally performing oxygen microelectrodes showed a current plateau in the range -0.6 to $-0.8 \mathrm{~V}$ with an output of approximately $70 \mathrm{pA}$ in air-saturated double-distilled water and of $2-5 \mathrm{pA}$ in

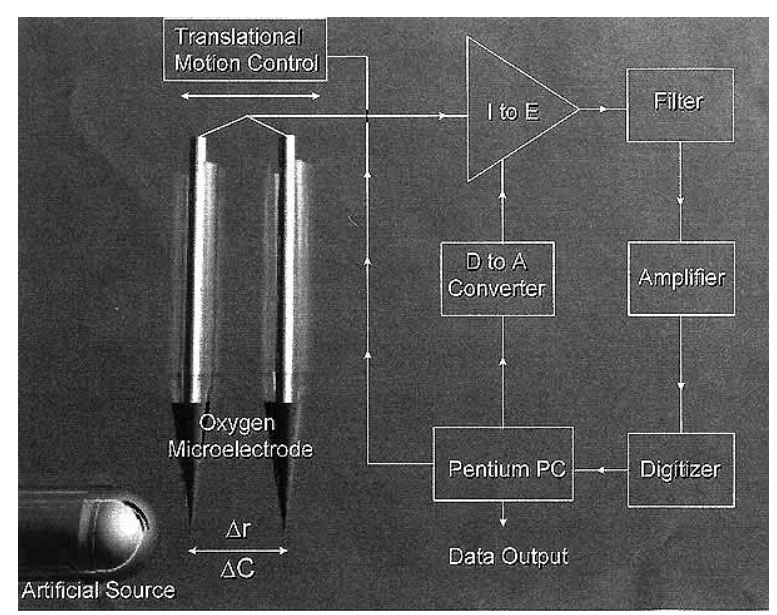

Fig. 1. Schematic diagram of the self-referencing oxygen electrode system and mode of operation within an oxygen gradient. I to E converts the current output from the probe into a voltage that can be processed by the subsequent systems. The D-to-A converter changes digital commands into analog signals and drives electrode polarization. $\Delta r$ represents the distance of electrode excursion and $\Delta C$ represents the difference in concentration between the extremes of the excursion of the electrode. 
$\mathrm{N}_{2}$-saturated pure water. Prior to use, new electrodes were conditioned at $-0.75 \mathrm{~V}$ for $1 \mathrm{~h}$ in double-distilled water, and performance was routinely assessed by observing current/voltage curves in air-saturated medium. A polarizing voltage for use during operation was chosen at the mid-point along the current plateau $(-0.75 \mathrm{~V})$.

The Serp oxygen electrode provides a continuous measurement of oxygen flux by measuring the oxygen concentration difference between two points perpendicular to a virtual oxygen source or sink, as in an artificial source of oxygen or nitrogen (Fig. 1) or the cell membrane. Although the operating principles behind the oxygen-selective Serp electrode technique are similar to the Seris system (Kühtreiber and Jaffe, 1991; Smith et al., 1994; Smith, 1995), the mode of relating signal output to a change in concentration is not. The Seris electrodes relate concentration to signal output in a Nernstian manner whereas, using the electrode construction originally described by Whalen et al. (1967), we find oxygen electrodes respond linearly $\left(\approx 0.271 \mathrm{pAl} / \mu \mathrm{mol}^{-1}\right.$ at $25^{\circ} \mathrm{C}$, $101 \mathrm{kPa}$ ) across the whole range of oxygen concentrations utilized. On the basis of these characteristics, the relationship between concentration and the current signal from an electrode being oscillated within an oxygen gradient is:

$$
C_{1}-C_{2}=\left(S I_{1}+b\right)-\left(S I_{2}+b\right),
$$

where $I$ is the electrode output (pA), $C$ is the oxygen concentration $\left(\mu \mathrm{mol} \mathrm{ml}^{-1}\right), S$ is the slope of the electrode calibration and $b$ is the $y$-intercept of the electrode calibration. The oxygen concentration (in $\mu \mathrm{mol} \mathrm{ml}^{-1}$ ) is calculated on the basis of the temperature, barometric pressure and salt concentration (Gnaiger and Forstner, 1983). This equation can be rearranged to the form:

$$
\Delta C=S \Delta I .
$$

$\Delta C$ can now be reconciled with the amplitude of electrode oscillation, $\Delta r(\mathrm{~cm})$, to obtain a measurement of oxygen flux (expressed in terms of $\mu \mathrm{mol} \mathrm{cm}{ }^{-2} \mathrm{~s}^{-1}$ ) employing the Fick equation (equation 1):

$$
J=-D \frac{S \Delta I}{\Delta r} .
$$

Data were collected as described previously (Smith et al., 1994) by using the current version of IonView software (BioCurrents Research Center, MBL, Woods Hole, MA). Measurements were made at a rate of 1000 data points per second. For each probe position, the probe signal is signalaveraged into 10 values consisting of 166 data points each. The frequency of the square wave oscillation was $0.3 \mathrm{~Hz}$ and has previously been shown to be slow enough to prevent disruption of the gradient, and to acquire an adequate electrode response, but fast enough to allow for noise filtering (Kühtreiber and Jaffe, 1990). Comparisons were made of values collected at each pole or extreme of translation. Three-tenths of the initial values, from each pole, were automatically discarded to eliminate movement artifacts and the period of gradient reestablishment after translation. For comparison of multiple treatments, analysis of variance (ANOVA) was performed using Tukey's honestly significant difference (HSD) test. Parallel treatments were analyzed using Student's $t$-test.

Artificial sources of $\mathrm{O}_{2}$ flux

To compare empirically determined oxygen flux (measured by the microelectrode in a self-referencing mode) with that measured statically, localized oxygen gradients were established radiating from a source pipette. The source pipette was constructed from a borosilicate glass micropipette (tip diameter $2-3 \mu \mathrm{m})$ connected to a Narishige microinjection system (model IM-200) by Teflon tubing. This served as a convenient means for purging the micropipette with gases of differing composition, maintaining constant line pressure, while ensuring that the gas-water interface was unbroken at the tip the source pipette without the production of bubbles. When pressurized with $\mathrm{O}_{2}$ or $\mathrm{N}_{2}$ gas, a diffusional field of oxygen was established around the pipette tip. This field was allowed to stabilize for $30-60 \mathrm{~min}$ before an oxygen microelectrode was positioned perpendicular to the tip of the source pipette, and static measurements of oxygen concentration were made at known points through the oxygen gradient until a constant background signal was obtained. The microelectrode was then returned to each static measurement position, and a differential signal was calculated from data obtained while oscillating the electrode as a square wave between two points in the same gradient, $10 \mu \mathrm{m}$ apart, at $0.3 \mathrm{~Hz}$.

The static oxygen concentrations within the diffusion field were modeled according to the following formula:

$$
C_{\mathrm{x}}=C_{\mathrm{b}}+\frac{\left(C_{\mathrm{s}}-C_{\mathrm{b}}\right) R}{R+x} .
$$

where $C_{\mathrm{x}}$ is the oxygen concentration at a given position, $C_{\mathrm{b}}$ is the background oxygen concentration in the dish, $C_{\mathrm{s}}$ is the oxygen concentration at the source, $R$ is the source radius, and $x$ is the distance from the source. This model was compared with the statically measured values (Fig. 2). The change in oxygen concentration between any two points within the oxygen gradient can now be determined mathematically using the differential of this theoretical equation and used to calculate flux by substitution of the $\Delta C$ value into the Fick equation. These flux values can then be compared with those measured using the electrode in a self-referencing mode.

\section{Neuronal oxygen flux}

The abdominal ganglion of Aplysia californica was removed under sterile conditions and incubated at $22^{\circ} \mathrm{C}$ for $18 \mathrm{~h}$ in artificial sea water (ASW) $\left(460 \mathrm{mmol}^{-1} \mathrm{NaCl}, 10.4 \mathrm{mmol}^{-1}\right.$ $\mathrm{KCl}, 27 \mathrm{mmoll}^{-1} \mathrm{MgCl}_{2}, 28 \mathrm{mmol}^{-1} \mathrm{MgSO}_{4}, 11 \mathrm{mmol}^{-1}$ $\mathrm{CaCl}_{2}, 5.5 \mathrm{mmol}^{-1}$ dextrose, $15 \mathrm{mmoll}^{-1}$ Hepes) containing $1.5 \%$ neutral protease. The neurons from the bag cell cluster were then dissociated and cultured at $18^{\circ} \mathrm{C}$ (Knox et al., 1992) in sterile ASW on sterile $22 \mathrm{~mm}$ diameter circular coverslips which formed the base of a center-well drilled into a $35 \mathrm{~mm} \times 10$ $\mathrm{mm}$ Falcon culture dish. After being cultured for $24-48 \mathrm{~h}$, these 


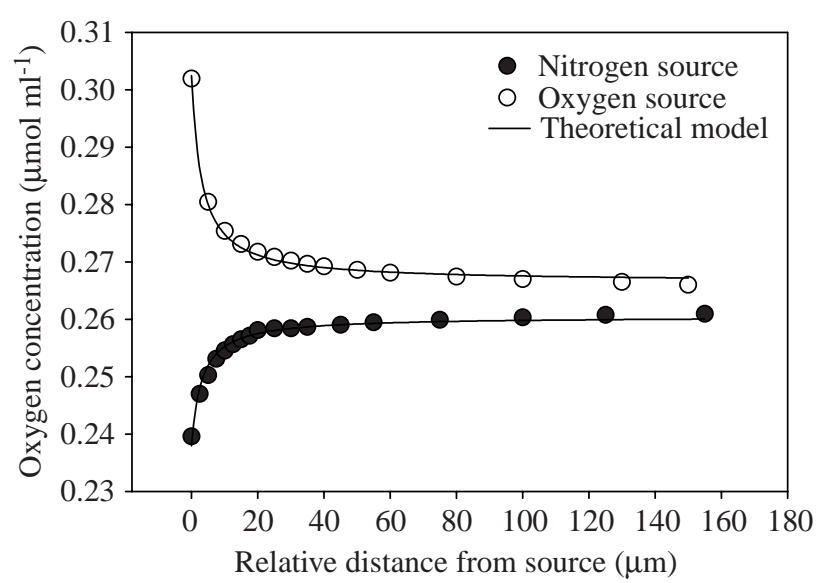

Fig. 2. Oxygen concentration as a function of distance from a source pipette (diameter $2-3 \mu \mathrm{m}$ ) as measured using a static electrode. Symbols represent measured values. The solid lines are the product of a theoretical model developed from first principles (see Materials and methods). The theoretical model can be used to calculate the change in oxygen concentration between any two points on the line through the flux field.

neurons had a diameters between 50 and $100 \mu \mathrm{m}$. Oxygen flux measurements were obtained by moving the electrode to within a few hundred nanometers of the cell membrane and oscillating the electrode tip orthogonally over an amplitude of $5 \mu \mathrm{m}$ at a frequency of $0.3 \mathrm{~Hz}$. Oxygen-specific current differences were converted to a measure of flux as described above.

To demonstrate the localized specificity of a detectable oxygen gradient around a neuron, step-back experiments were performed where the self-referencing electrode was moved to positions at increasing distances from the cell membrane. To demonstrate the dependence of the measured extracellular oxygen flux on mitochondrial respiration, cells were microinjected with a metabolic uncoupling cocktail ( $100 \mu \mathrm{mol}^{-1}$ 2,4-dinitrophenol, $1 \mathrm{mmol}^{-1}$ sodium pyruvate, $1 \mathrm{mmoll}^{-1}$ adenosine diphosphate in ASW) followed by inhibition of respiration by the cytochrome $c$ oxidase inhibitor $\mathrm{KCN}\left(1 \mathrm{mmoll}^{-1}\right.$ in ASW). The cell soma was impaled with a $2 \mu \mathrm{m}$ tip microinjection pipette connected to a Narishige microinjection system (model IM-200). Internal holding pressure during pipette entry into the cell was maintained positive at $3.45 \mathrm{kPa}$ and was reduced to zero once the pipette was visibly through the cell membrane (assessed by withdrawing the pipette a few micrometers and noting a membrane seal around the pipette tip). After insertion of the uncoupling-cocktail pipette, background oxygen flux measurements were taken $100 \mu \mathrm{m}$ from the 'at cell' measuring position. The oxygen probe was then positioned next to the cell membrane, and a pre-injection steady-state recording of oxygen flux was obtained from the neuronal soma. This was followed by two injection bursts of 20 and $40 \mathrm{~ms}$ duration with oxygen flux monitored over $5 \mathrm{~min}$ between each burst. The microinjection pipette was then withdrawn, and oxygen flux was subsequently monitored for a further $10 \mathrm{~min}$. A second micropipette containing $\mathrm{KCN}$ was then inserted into the cell, and the injection procedure was repeated. In a parallel series of control experiments, oxygen flux was followed during microinjection of ASW following 20 and $40 \mathrm{~ms}$ injections.

\section{Oxygen flux from Spirogyra greveilina}

The filamentous green alga Spirogyra greveilina was chosen as an additional test organism. Given that this is a photosynthetic organism, oxygen flux measurements derived from cellular activity should be directly manipulated with light. Cultures of Spirogyra greveilina (Carolina Biological, product number 15-2525, Burlington, NC, USA) were grown in soil-water medium (James, 1978) and stored at room temperature $\left(21^{\circ} \mathrm{C}\right)$, under fluorescent lighting, until used for experimentation a few days later. For oxygen flux recordings, the filaments were maintained in soil-water medium (Carolina Biological, product number 15-3785, Burlington, NC, USA) at $23^{\circ} \mathrm{C}$ in $35 \mathrm{~mm} \times 10 \mathrm{~mm}$ Falcon culture dishes modified with a $22 \mathrm{~mm}$ circular coverslip which formed the base of a centerwell drilled in the dish. For measuring oxygen flux, the probe was moved at $0.3 \mathrm{~Hz}$ over a distance of $10 \mu \mathrm{m}$. Lighting was provided by the microscope and was set at $220 \mu \mathrm{mol} \mathrm{m}^{-2} \mathrm{~s}^{-1}$ unless noted otherwise. To test the spatial resolution of the technique, the probe was moved to positions along a single cell in relation to the position of the spiral chloroplasts within the cell. Measurements were taken both at and between adjacent segments of the spiralling chloroplasts. For the real-time response experiments, the probe was moved to a position in the middle of a single cell. The probe was then maintained at this position as the light was intermittently turned on and off.

Values are presented as means \pm S.E.M. unless stated otherwise.

\section{Results \\ Artificial sources of oxygen flux}

The change in oxygen concentration with distance from an $\mathrm{O}_{2}$ and $\mathrm{N}_{2}$ source pipette is demonstrated in Fig. 2. Once the gradient had stabilized, the static electrode was moved to points away from the source pipette to obtain measurements of oxygen concentration. By relating the change in $\mathrm{O}_{2}$ concentration over a given distance, using non-linear analysis, a static measurement of oxygen flux was derived. By returning to each position, then oscillating the same electrode within the oxygen gradient, a direct measurement of the flux was obtained. The match between the values generated using the static and directly measured fluxes was then used to define the efficiency with which the self-referencing electrode reproduces a signal differential as related to oxygen flux. Comparisons of measured fluxes with those determined from the static measurements typically showed that the self-referencing electrode measurements underestimated oxygen flux by approximately $9.5-32 \%$. These values were characteristic of individual electrodes and were taken into account in all calculations of oxygen flux in this paper. Fig. 3 shows the measured patterns of oxygen flux compared with those 


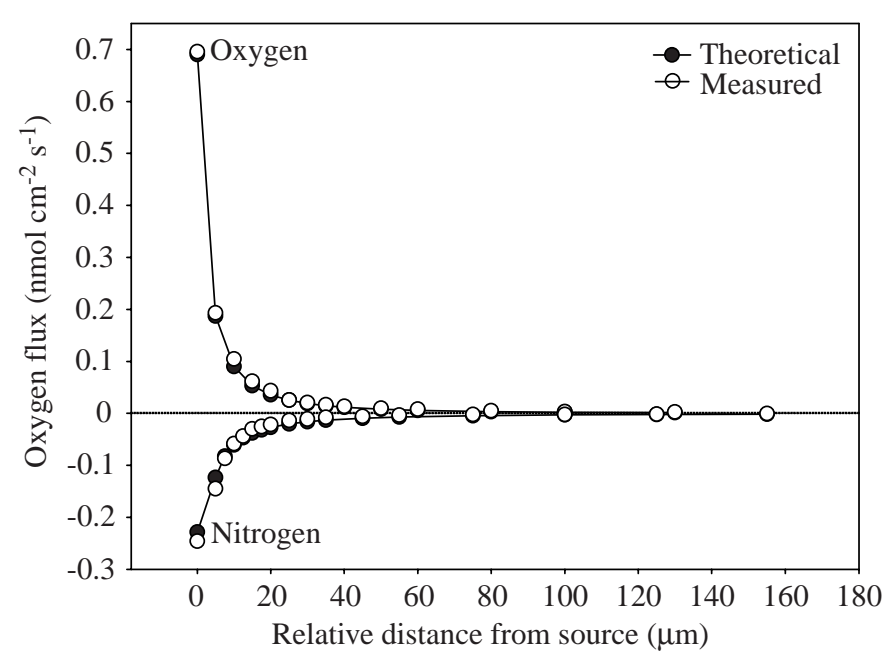

Fig. 3. Comparison of theoretical and measured oxygen flux as a function of distance from an artificial source pipette (diameter $2 \mu \mathrm{m}$ ). Excursion distance $10 \mu \mathrm{m}$; frequency $0.3 \mathrm{~Hz}$. This frequency of oscillation clearly allows the re-establishment of the gradient after movement, while minimizing the impact of drift on the electrode. Theoretical values were calculated using the model data in Fig. 2. The differential of the theoretical modeling equations can be used to calculate differential oxygen concentration and flux through any point on the line through the flux field.

calculated using the static measurements. The final leastsquares regression between the two data sets yields an $r^{2}$ value of 0.99 .

\section{Neuronal oxygen flux}

Given that oxygen fluxes are easily measured from an artificial source, and that the self-referencing flux measurements closely match those predicted from static values, we set out to measure oxygen flux from single cells using the bag cell neuron of Aplysia californica as a model system. At $1 \mu \mathrm{m}$ outwards from the point of contact with the cell membrane, a consistent current differential of $-30 \mathrm{fA}$ was measured. This was repeatedly obtained after moving the electrode to a background position $100 \mu \mathrm{m}$ away and then returning to the 'at cell' position (Fig. 4). Gradual movement of the electrode outwards from the cell soma yielded a graded transition between the 'at cell' flux and the background value. When flux measurements were taken at specific positions along a line perpendicular to the cell membrane, an exponential fall in oxygen flux was measurable as the electrode was moved outwards in the oxygen gradient (Fig. 5). The profile of the oxygen gradient shown in Fig. 5 clearly shows that the $5 \mu \mathrm{m}$ amplitude lies entirely within the gradient. For an electrode oscillating over $5 \mu \mathrm{m}$, flux measurements at the closest point of approach to the membrane averaged $11.46 \pm 1.43 \mathrm{pmol} \mathrm{cm}^{-2} \mathrm{~s}^{-1}$ (multiple measurements from seven cells with 50 data points taken at each cell), corresponding to an oxygen differential of $231.0 \pm 29.0 \mathrm{pmol} \mathrm{ml}^{-1}$. A stable background level was measured at a distance of $30 \mu \mathrm{m}$ from the soma.

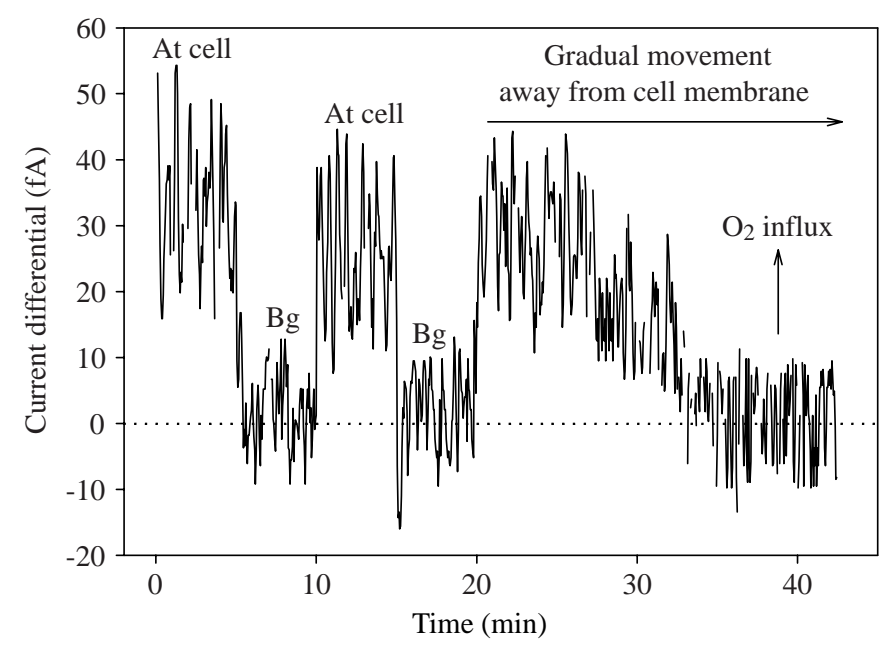

Fig. 4. The appearance of raw data collected from a cultured Aplysia californica bag cell neuron at $23^{\circ} \mathrm{C}$. Excursion distance $5 \mu \mathrm{m}$; frequency $0.3 \mathrm{~Hz}$. When in the 'at cell' position, the electrode was within $1 \mu \mathrm{m}$ of the plasmalemma. $\mathrm{Bg}$ stands for data collected at a background position $100 \mu \mathrm{m}$ away from the cell membrane.

To confirm that the oxygen flux measured resulted from the net effect of mitochondrial oxygen consumption, cells were exposed to an uncoupling cocktail followed by $\mathrm{KCN}$. Microinjection was used to deliver the cocktail to specific locations of the cell and, most importantly, enabled the oxygen electrode to be isolated from the applied agents. As a result, there was no chance of affecting electrode performance by exposure to either dinitrophenol or KCN. Parallel control experiments were conducted to observe the effects of saline microinjection alone. Fig. 6 demonstrates increases in oxygen flux rates after 20 and $40 \mathrm{~ms}$ bursts of uncoupling cocktail, which became maximal when measured $10 \mathrm{~min}$ after the $40 \mathrm{~ms}$ burst. Note that there was no apparent effect of insertion of the

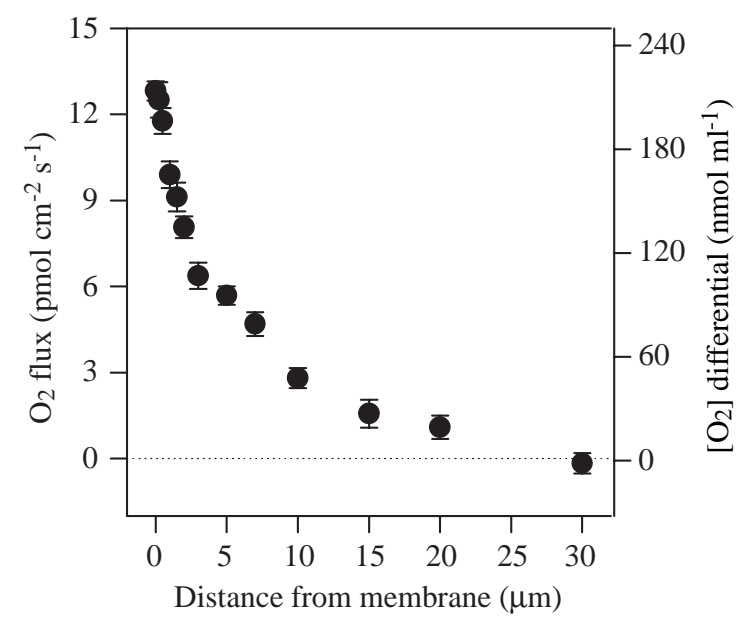

Fig. 5. Oxygen gradient and oxygen flux in relation to the distance from the membrane of an Aplysia californica bag cell neuron. Data were collected by oscillating the electrode over a $5 \mu \mathrm{m}$ excursion at $0.3 \mathrm{~Hz}$. Each data point is the mean \pm S.E.M. of 50 data points collected at each position. 


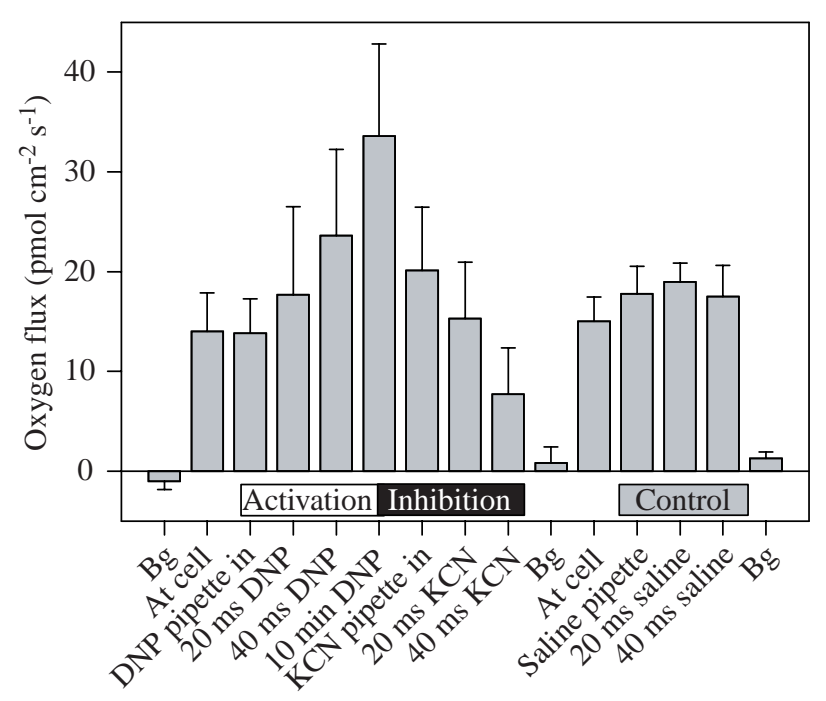

Fig. 6. Effect of microinjection of metabolic substrates and $\mathrm{KCN}$ on $\mathrm{O}_{2}$ flux into Aplysia californica bag cell neurons. Bg stands for data collected at a background position $100 \mu \mathrm{m}$ away from the cell membrane. The oxygen probe was positioned next to the cell membrane, and a pre-injection steady-state recording of oxygen flux was obtained (at cell) from the neuronal soma. This was followed by two injection bursts of a metabolic uncoupling cocktail (DNP) containing $100 \mu \mathrm{moll}^{-1} \quad$ 2,4-dinitrophenol, $1 \mathrm{mmoll}^{-1}$ sodium pyruvate and $1 \mathrm{mmoll}^{-1}$ adenosine diphosphate in artificial sea water. These injections were of $20 \mathrm{~ms}(20 \mathrm{~ms}$ DNP) and $40 \mathrm{~ms}(40 \mathrm{~ms}$ DNP) duration, and oxygen flux was monitored over 5 min between each burst. The microinjection pipette was then withdrawn, and oxygen flux was subsequently monitored for a further $10 \mathrm{~min}(10 \mathrm{~min}$ $\mathrm{DNP}$ ). A second micropipette containing $\mathrm{KCN}$ was then inserted into the cell, and the injection procedure was repeated $(20 \mathrm{~ms} \mathrm{KCN}$ and $40 \mathrm{~ms} \mathrm{KCN}$ ). In a parallel series of control experiments, oxygen flux was followed during microinjection of artificial sea water $(20 \mathrm{~ms}$ saline, and $40 \mathrm{~ms}$ saline). The probe was operated over a $5 \mu \mathrm{m}$ excursion at $0.3 \mathrm{~Hz} . \mathrm{N}=3$ for both experimental and control groups. Values are means + S.E.M.

uncoupling cocktail micropipette on oxygen flux prior to the first injection burst. Subsequent injection of KCN reversed the metabolic activation, with measured oxygen fluxes returning to control values after a $40 \mathrm{~ms}$ burst. Parallel experiments detailing microinjection of artificial sea water following 20 and $40 \mathrm{~ms}$ bursts showed no significant effect. The results indicate that the changes in oxygen flux observed in the preceding experiments were due to metabolic activation and reversal of this activation.

\section{Oxygen flux from Spirogyra greveilina}

The spatial capabilities of the system were demonstrated in the experiments conducted with Spirogyra greveilina. The probe could easily discriminate differences in oxygen flux between positions relative to the placement of the chloroplast (Fig. 7) while the measuring positions averaged $10.6 \pm 1.8 \mu \mathrm{m}$ apart. Flux values averaged $13.3 \pm 0.4 \mathrm{pmol} \mathrm{cm}^{-2} \mathrm{~s}^{-1}$ at the chloroplast and $11.4 \pm 0.4 \mathrm{pmol} \mathrm{cm}^{-2} \mathrm{~s}^{-1} \quad(N=20)$ between chloroplasts. Real-time recordings of the changes in flux

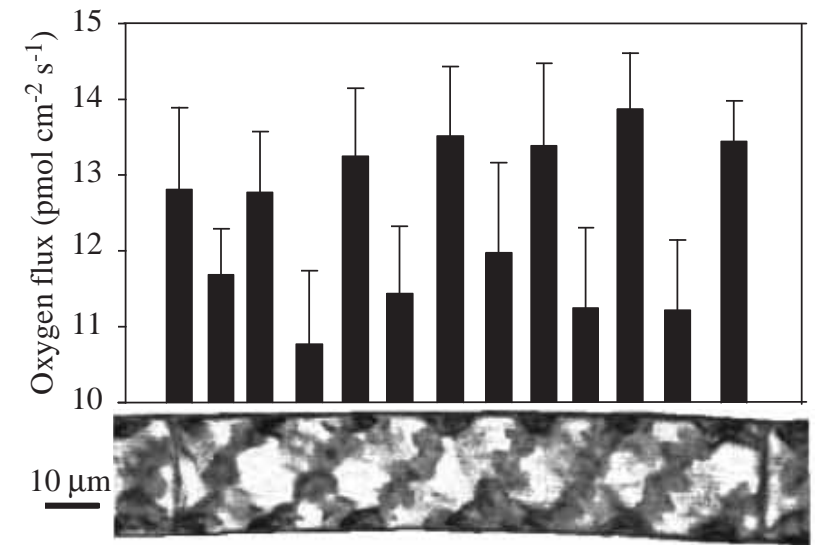

Actual measuring position along the cell

Fig. 7. Differences in photosynthetic oxygen efflux measured in relation to the position of the chloroplasts of Spirogyra greveilina. In this particular species, a pair of chloroplasts (dark structures in the photograph) winds helically within the cell. The probe was moved to a position just outside the cell wall at the indicated positions. The probe was operated over a $10 \mu \mathrm{m}$ excursion at $0.3 \mathrm{~Hz}$. Data shown are from a representative experiment that was replicated five times using different cells. Values for each position are means + S.D. of 20 data points.

(Fig. 8) demonstrated the relationship between light-dependent oxygen evolution and measured oxygen flux. When the light was on, outward fluxes of oxygen averaged $13.9 \pm 1.68 \mathrm{pmol} \mathrm{cm}^{-2} \mathrm{~s}^{-1}$, while in the dark the direction of oxygen movement reversed and averaged 1.80 \pm 0.84 pmol cm${ }^{-2} \mathrm{~s}^{-1}(N=20)$.

\section{Discussion}

The validity of testing the performance of self-referencing electrodes against an artificially generated gradient was initially established for ion-selective electrodes where passive diffusion acted as the main driving force for the ionic species of interest from a point within a fixed column of source material (Kühtreiber and Jaffe, 1990). Baumgärtl et al. (1974) used a $1.5 \mathrm{~mm}$ platinum wire electrode to create an artificial oxygen diffusional field in agarose medium. Our approach differed in that the source was composed of a gas of known composition which diffused from the gas-liquid interface maintained at the tip of the glass holding pipette into the surrounding aqueous medium. Using this artificial source, we found that the flux values obtained from the electrode operating in the self-referencing mode closely matched theoretical values obtained from conventional static measurements (Fig. 3). This demonstrated that the system reliably measures oxygen concentration differentials in an artificial gradient.

The ability of this technique to measure fluxes from biological sources was tested next. We measured oxygen flux from different cell types under various metabolic conditions. With isolated Aplysia californica neurons, the probe was able 


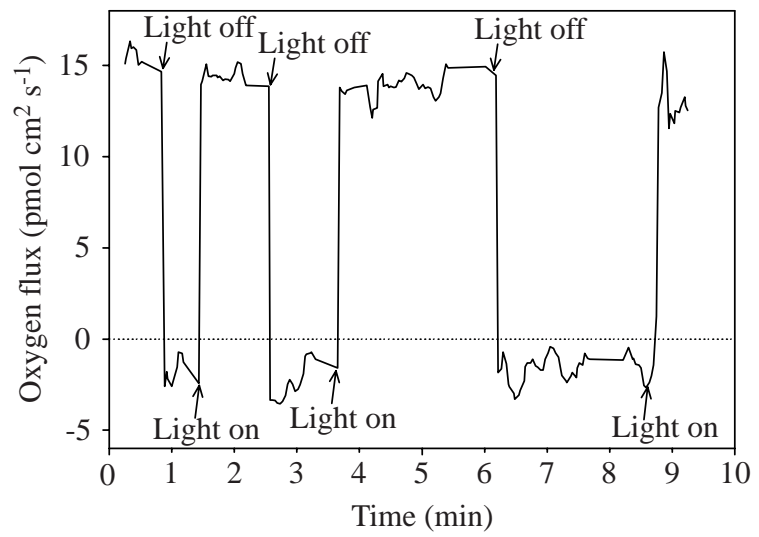

Fig. 8. The real-time changes in photosynthetically induced oxygen efflux from a single cell of Spirogyra greveilina in response to changes in lighting. The probe was maintained at a position next to a chloroplast at the center of a cell while the microscope light was turned on and off. The probe was operated over a $10 \mu \mathrm{m}$ excursion at $0.3 \mathrm{~Hz}$. The data are from a representative experiment that was replicated five times using different cells.

to detect a two- to threefold metabolic activation of oxidative phosphorylation in response to microinjection of dinitrophenol, followed by an inhibition in response to microinjection of $\mathrm{KCN}$. In the photosynthetic green algae Spirogyra greveilina, oxygen evolution depended on lighting and on the position of the probe relative to the chloroplast. When the measured values for oxygen flux are converted, using simple assumptions for transporting surface area and mass, there is good agreement between the results of the present study and the limited comparable data in the literature. For example, if we assume a hemispherical shape with a depth of $50 \mu \mathrm{m}$ for the neuron, calculate the non-adhering surface area and volume, while attributing a mass equivalent to that of water, a rate of oxygen consumption of $11.5 \mathrm{pmol} \mathrm{cm}^{-2} \mathrm{~s}^{-1}$ can be converted to a value $0.42 \mathrm{mmol} \mathrm{kg}^{-1} \mathrm{~min}^{-1}$. This compares favorably with the values for resting non-myelinated rabbit vagus nerve $\left(0.484 \mathrm{mmol} \mathrm{kg}^{-1} \mathrm{~min}^{-1}\right)$ and garfish olfactory nerve $\left(0.206 \mathrm{mmol} \mathrm{kg}^{-1} \mathrm{~min}^{-1}\right)$ measured by Ritchie and Straub (1979, 1980). Note that the neurons used in the present study had been in culture for between 24 and $48 \mathrm{~h}$ and were in a resting state (Knox et al., 1992). Similarly, if we calculated the transporting surface area of the Spirogyra greveilina cell as a cylinder of diameter of $30 \mu \mathrm{m}$ and length $100 \mu \mathrm{m}$, ignoring the ends, we have a rate of oxygen consumption of $2.66 \times 10^{-5} \mathrm{pmolcell}^{-1} \mathrm{~s}^{-1}$. This compares with a value of $3.18 \times 10^{-5}$ pmol cell $^{-1} \mathrm{~s}^{-1}$ calculated from the data in Weger et al. (1996) for the unicellular algae Selenastrum minutum.

We found that the most critical factors affecting accurate measurement of oxygen flux from single cells were the distance from the plasma membrane and the amplitude of electrode oscillation. Meaningful measurements of oxygen flux require accurate electrode positioning near the plasma membrane because flux values are reported on the basis of unit area of the membrane. Furthermore, the amplitude of electrode oscillation must occur over a distance that lies entirely within the oxygen gradient. As the amplitude is increased through an extracellular gradient, the differential signal increases to a point where one of the extremes of electrode positioning lies outside the gradient. Continuing to increase the amplitude of oscillation beyond this point will result in an underestimation of flux as $\Delta r$ continues to increase.

The measurement of oxygen flux from a single cell also depends on the metabolic and physical characteristics of oxygen diffusion into the cell along a net oxygen gradient established under atmospheric oxygen saturation. Particularly important is the relationship between the metabolic state of the cell, the net volume of mitochondria and/or chloroplasts around the site of measurement and the shape of the cell itself. Since the volume of mitochondria and/or chloroplasts within the region of measurement represents a constant, changes in $\Delta C$ will only result from shifts in net oxygen metabolism, making $\Delta C / \Delta r$ the primary variable in the calculation of oxygen flux. This assumes a constant coefficient for the diffusion of oxygen. Inside the cell, it is not clear whether this is necessarily the case. The high solubility and diffusion characteristics of oxygen within lipid bilayers have been suggested actually to conduct oxygen towards the principle sinks, with variance in the value of $D$ according to the distribution, composition and phase characteristics of organellar membranes (Longmuir, 1980; Dutta and Popel, 1995). Since the self-referencing oxygen electrode measures the oxygen gradient in the aqueous medium adjacent to the outer surface of the plasma membrane, the rate of oxygen diffusion is assumed to be constant over the distance of electrode oscillation, approximating that through water at $25^{\circ} \mathrm{C}$. The application of $\Delta C$ and $D$ to the Fick equation therefore provides an accurate assessment of the rate of transfer of oxygen towards the plasma membrane and the mitochondrial mass.

In conclusion, we have developed a sensitive and noninvasive technique for measuring the magnitude of oxygen flux localized to specific regions of the plasma membrane of single cultured cells. Our results suggest that the oxygen signal obtained approximates the oxygen gradient from the extracellular environment into the cytoplasm, such that these measurements reflect oxygen flux resulting from metabolic activity of mitochondria or chloroplasts local to the region of measurement. This technique allows the regional mapping of rates of cellular oxygen consumption or production and, with multiple spatially distinct measurements, an estimation of total cellular oxygen exchange. Values for oxygen flux and wholecell oxygen consumption fall within the range of those expected from studies in the literature. The great advantage of this approach is that it provides simultaneous temporal and spatial resolution of oxygen flux without contact or interference around the cell. This approach will prove invaluable as a high-resolution tool for exploring the cellular events associated with metabolic function.

We gratefully acknowledge the assistance of Kasia 
Hammar for her help with Aplysia californica bag cell culture, and T. K. Goldstick for comments on the draft manuscript and help with developing the theoretical models. This work was funded by Council for Tobacco Research USA Inc. and Lakian Fellowship awards to S.C.L. and NIH grant P41 RR01395 to P.J.S.S.

\section{References}

Armstrong, W. (1994). Polarographic oxygen electrodes and their use in plant aeration studies. Proc. R. Soc. Edinb. 102, 511-527.

Baumgärtl, H., Grunewald, W. and Lübbers, D. (1974). Polarographic determination of oxygen partial pressure field by $\mathrm{Pt}$ microelectrodes using the $\mathrm{O}_{2}$ field in front of a $\mathrm{Pt}$ macroelectrode as a model. Pflügers Arch. 347, 49-61.

Boag, J. W. (1969). Oxygen diffusion and oxygen depletion problems in radiobiology. Curr. Topics Rad. Res. 5, 141-195.

Davies, P. W. and Brink, F. (1942). Microelectrodes for measuring local oxygen tension in animal tissues. Rev. Sci. Instr. 13, 524-533.

Dutta, A. and Popel, A. S. (1995). A theoretical analysis of intracellular oxygen diffusion. J. Theor. Biol. 175, 433-445.

Gnaiger, E. (1983). Calculation of equilibrated oxygen concentration. In Polarographic Oxygen Sensors (ed. E. Gnaiger and H. Forstner), pp. 334-336. Heidelberg: Springer Verlag.

Jaffe, L. F. and Nuccitelli, R. (1974). An ultrasensitive vibrating probe for measuring steady extracellular currents. J. Cell Biol. 63, 614-628.

James, D. E. (1978). Culturing Algae. Burlington, NC: Carolina Biological Company.

Keefe, D. L. (1997). Aging and infertility in women. Med. Health R.I. 80, 403-405.

Knox, R. J., Quattrocki, E. A., Connor, J. A. and Kaczmarek, L. K. (1992). Recruitment of $\mathrm{Ca}^{2+}$ channels by protein kinase $\mathrm{C}$ during rapid formation of putative neuropeptide release sites in isolated Aplysia neurons. Neuron 8, 883-889.

Krogh, A. (1919). The rate of diffusion of gases through animal tissues, with some remarks on the coefficient of invasion. $J$. Physiol., Lond. 52, 391-408.

Kühtreiber, W. M. and Jaffe, L. F. (1990). Detection of extracellular calcium gradients with a calcium-specific vibrating electrode. J. Cell Biol. 110, 1565-1573.
Longmuir, I. S. (1980). Channels of oxygen transport from blood to mitochondria. Adv. Physiol. Sci. 25, 19-22.

Malchow, R. P., Land, S. C., Patel, L. S. and Smith, P. J. S. (1997). Consumption of oxygen by isolated skate retinal photoreceptors. Biol. Bull. 193, 231-232.

Mignotte, B. and Vayssiere, J. L. (1998). Mitochondria and apoptosis. Eur. J. Biochem. 252, 1-15.

Poitry, S., Tsacopoulos, M., Fein, A. and Cornwall, M. C. (1996). Kinetics of oxygen consumption and light-induced changes of nucleotides in solitary rod photoreceptors. J. Gen. Physiol. 108, $75-87$.

Ritchie, J. M. and Straub, R. W. (1979). Phosphate efflux and oxygen consumption in small non-myelinated nerve fibres at rest and during activity. J. Physiol., Lond. 287, 315-327.

Ritchie, J. M. and Straub, R. W. (1980). Oxygen consumption and phosphate efflux in mammalian non-myelinated nerve fibres. $J$. Physiol., Lond. 304, 109-121.

Schneiderman, G. and Goldstick, T. K. (1978). Oxygen electrode design criteria and performance characteristics: recessed cathode. J. Appl. Physiol. 45, 145-154.

Silver, I. A. (1967). Problems in the investigation of tissue oxygen microenvironment. In Chemical Engineering in Medicine (ed. D. Reneau), pp. 343-351. Washington, DC: American Chemical Society.

Sims, N. R. (1996). Energy metabolism, oxidative stress and neuronal degeneration in Alzheimer's disease. Neurodegeneration 5, 435-440.

Smith, P. J. S. (1995). Non-invasive ion probes: tools for measuring transmembrane ion flux. Nature 378, 645-646.

Smith, P. J. S., Sanger, R. H. and Jaffe, L. J. (1994). The vibrating $\mathrm{Ca}^{2+}$ electrode: A new technique for detecting plasma membrane regions of $\mathrm{Ca}^{+2}$ influx and efflux. Meth. Cell Biol. 40, 115-134.

Suomalainen, A. (1997). Mitochondrial DNA and disease. Ann. Med. 29, 235-246.

Weger, H. G., Lynnes, J. A. and Torkelson, J. D. (1996). Characterization of extracellular oxygen consumption by the green algae Selenastrum minutum. Physiol. Plant. 96, 268-274.

Whalen, W. J. (1974). Some problems with an intracellular $P_{\mathrm{O}_{2}}$ electrode. Adv. Exp. Med. Biol. 50, 39-41.

Whalen, W. J., Riley, J. and Nair, P. (1967). A microelectrode for measuring intracellular $P_{\mathrm{O}_{2}}$. J. Appl. Physiol. 23, 798-801. 